\title{
Mould exposure at home relates to inflammatory markers in blood
}

\author{
L. Beijer, J. Thorn, R. Rylander
}

Mould exposure at home relates to inflammatory markers in blood. L. Beijer, J. Thorn, R. Rylander. (C) ERS Journals Ltd 2003.

ABSTRACT: Living in damp buildings has been associated with airway symptoms, suspected to be due to inflammatory reactions. The relationship between home exposure to mould and signs of inflammation was, therefore, studied.

Nonsmoking subjects with a high (G-high, $>4.0 \mathrm{ng} \cdot \mathrm{m}^{-3}, \mathrm{n}=17$ ) or low (G-low, $\left.<2.0 \mathrm{ng} \cdot \mathrm{m}^{-3}, \mathrm{n}=18\right)$ amount of airborne $\beta(1 \rightarrow 3)$-D-glucan, an indicator of mould biomass, in the home were recruited. Blood samples were analysed for granulocytic enzymes, T-cell subsets and the secretion of cytokines from in vitro incubated peripheral blood mononuclear cells (PBMCs).

In the G-high group, the proportion of cytotoxic T-cells $(\mathrm{CD8}+\mathrm{S6F1}+)$ was lower and secretion of tumour necrosis factor- $\alpha$ from PBMCs higher than in the G-low group. There were no significant differences in secretion of interferon gamma and interleukin (IL)-4 from PBMCs between the two groups. Among nonatopic subjects, the ratio between interferon gamma and IL-4 was significantly higher in the G-high group than in the G-low group and was related to the amount of $\beta(1 \rightarrow 3)$-D-glucan in the home. No significant differences were found regarding secretion of IL-10 or IL-1 $\beta$ from PBMCs, eosinophil cationic protein or myeloperoxidase in serum, or differential cell counts in blood.

The effects found on inflammatory markers in relation to $\beta(1 \rightarrow 3)$-D-glucan in the home suggest upregulation of some parts of the inflammatory/immunological system due to mould exposure.

Eur Respir J 2003; 21: 317-322. Dept of Environmental Medicine,
Sahlgrenska Academy, Göteborg University, Göteborg, Sweden.

Correspondence: L. Beijer, Dept of Environmental Medicine, Box 414, SE 40530 Göteborg, Sweden.

Fax: 4631825004

E-mail: lena.beijer@envmed.gu.se

Keywords: Cytotoxic T-cell

$\beta(1 \rightarrow 3)$-D-glucan

interferon gamma

interleukin-4

mould

tumour necrosis factor- $\alpha$

Received: October 12001

Accepted after revision: August 82002

This study was supported by the Vardal Foundation, Stockholm, Sweden, (grant A96 082) and the Swedish Heart-Lung Foundation, Stockholm, Sweden, (grant 199941383).
Numerous reports describe an association between living in damp buildings and the presence of symptoms in the airways as well as general fatigue and headache [1-3]. Some studies have shown an increased risk of asthma in children and adults [4-6]. Increased indoor humidity creates the conditions for growth of microorganisms, and the presence of mould growth has often been reported in association with symptoms. The mechanism behind these symptoms could thus be related to an increased inflammatory reaction in the airways in response to inhaled microorganisms or substances derived from these [7].

Most previous studies on health effects associated with living or working in damp and/or mouldy buildings have used questionnaires to assess the prevalence of symptoms. A few studies have performed objective measurements of health effects such as changes in lung function, airway reactivity or markers of inflammation in body compartments. In atopic children with asthma, peak expiratory flow variability was associated with the amount of $\beta(1 \rightarrow 3)$-D-glucan relative to the living room floor area [8]. Increased levels of tumour necrosis factor- $\alpha(\mathrm{TNF}-\alpha)$, interleukin (IL)- 6 and nitric oxide in the nasal lavage fluid of school staff were related to staying in a mould-contaminated school [9]. Myeloperoxidase (MPO) levels in serum were increased among subjects living in houses with
$>1 \mathrm{ng}$ airborne $\beta(1 \rightarrow 3)$-D-glucan $\cdot \mathrm{m}^{-3}$ compared to subjects exposed to $<1 \mathrm{ng}$ airborne $\beta(1 \rightarrow 3)$-D-glucan $\cdot \mathrm{m}^{-3}$ [10].

Exposure to indoor moulds has also been associated with effects on the immune system and is a possible risk factor for atopic sensitisation to airborne allergens. In a study among children, an increased number of memory T-cells and a reduced CD4/CD8 ratio were related to mould exposure in the home [11]. In a study of children from Germany, reporting of dampness and mould in the dwelling was associated with a higher frequency of atopic sensitisation [12]. Indoor exposure to aspergillus was a risk factor for atopy in a cohort of Australian children [13] and a study from Finland showed an increased prevalence of atopy among mouldexposed schoolchildren [14].

In order to further evaluate the effects of mould exposure at home on the inflammatory and immune system, a study was performed among persons living in homes with high (G-high) or low (G-low) levels of airborne $\beta(1 \rightarrow 3)$-D-glucan. This polyglucose compound, present in the cell wall of fungi, was used as an indicator of the total airborne mould biomass. Clinical effects were assessed by measuring levels of inflammatory markers and numbers of lymphocyte subsets in blood and secretion of cytokines from cultivated peripheral blood mononuclear cells (PBMCs). 


\section{Methods}

\section{Subjects}

Subjects for the study were recruited from a previous investigation in an area of terraced housing [10] and by advertising in the local press, seeking persons with mould problems in their homes. Inclusion criteria were an age of 19-65 yrs, nonsmokers and the absence of physician-diagnosed asthma or diseases requiring medication. The Ethics Committee of the Faculty of Medicine at Göteborg University, Göteborg, Sweden, approved the study and all participating subjects gave their informed consent.

The amount of airborne $\beta(1 \rightarrow 3)$-D-glucan in the subjects' homes was measured and two groups were defined within the recruited population, those with $<2.0 \mathrm{ng} \beta(1 \rightarrow 3)$-D-glucan $\cdot \mathrm{m}^{-3}$ in their homes (G-low) and those with $>4.0 \mathrm{ng} \beta(1 \rightarrow 3)$-D-glucan $\cdot \mathrm{m}^{-3}$ (G-high), 35 subjects in all. The limits used for high and low exposure were based on the results from the previous terraced housing study, in which $30 \%$ of the 75 houses examined had a $\beta(1 \rightarrow 3)$-D-glucan level of $>4 \mathrm{ng} \cdot \mathrm{m}^{-3}$ and $30 \%$ of $<2.0 \mathrm{ng} \cdot \mathrm{m}^{-3}[10]$.

One person was recruited from each home, except for three homes in the G-low group and two in the G-high group, where couples participated. Of the 21 persons recruited by advertising, $43 \%$ were classified into the G-high group, and, of the 14 persons recruited from the previous study, $57 \%$ were classified into the G-high group according to the criteria described above.

Table 1 shows home $\beta(1 \rightarrow 3)$-D-glucan levels and subject characteristics.

Two blood samples were taken from each subject for analysis of serum marker levels and cytokine secretion from PBMCs. The samples were taken at an interval of $2-3$ weeks and the mean of the two measurements used for each person. Lymphocyte subtyping was performed using a single blood sample from each subject.

\section{Determination of $\beta(1 \rightarrow 3)$-D-glucan levels}

Airborne dust was created using a machine designed to whirl up dust approximately equivalent to that generated by a few people moving about in a room [15]. The dust generator was run for $5 \mathrm{~min}$ and this was followed by a 10 -min pause. Two such periods were used for the sampling. Duplicate air samples

Table 1.-Home $\beta(1 \rightarrow 3)$-D-glucan levels and subject characteristics

\begin{tabular}{lcc}
\hline & G-low & G-high \\
\hline Subjects n & 18 & 17 \\
Homes n & 15 & 15 \\
$\beta(1 \rightarrow 3)$-D-glucan ng.m ${ }^{-3}$ & $0.9(0.2-1.9)$ & $6.0(4.1-51.7)$ \\
Females n (\%) & $9(50)$ & $6(35)$ \\
Atopics n (\%) & $6(33)$ & $5(29)$ \\
Age yrs & $52(26-66)$ & $45(19-59)$ \\
\hline
\end{tabular}

Data are presented as absolute values with or without percentages in parenthesis or as median (range). were taken in this 30 min period by drawing air through polycarbonate filters with a pore size of $0.8 \mu \mathrm{m}$ (Isopore $\mathrm{R}$; Millipore, Inc., Boston, MA, USA) mounted side-by-side $0.8 \mathrm{~m}$ above the floor at a rate of $5 \mathrm{~L} \cdot \mathrm{min}^{-1}$. Two rooms were investigated in each home. The bedroom was sampled in 25 of the 30 homes and the living room in 26 homes. Other rooms sampled were workrooms, dining rooms and basements.

The filters were shaken for $10 \mathrm{~min}$ in $10 \mathrm{~mL} 0.3 \mathrm{M}$ sodium hydroxide in pyrogen-free water on ice in order to unwind the triple helical structure of the $\beta(1 \rightarrow 3)$-D-glucan and make it water-soluble. The solution was then analysed using a $\beta(1 \rightarrow 3)$-D-glucanspecific Limulus lysate [16]. Filter extract samples of $50 \mu \mathrm{L}$ were placed in a microwell plate and $50 \mu \mathrm{L}$ specific $\beta(1 \rightarrow 3)$-D-glucan lysate (Fungitic G Test $(\mathbb{R}$; Seikagaku Corp., Tokyo, Japan) were added. The plate was incubated in a spectrophotometer (Well reader $($; ; Scinics Corp., Tokyo, Japan), and the kinetics of the ensuing colour reaction read photometrically, transformed into absorbance units and compared to a standard curve created using the Fungitech G TE Reference Standard (Seikagaku Corp.). The results were expressed in nanograms per millilitre of liquid and the detection limit was $20 \mathrm{pg} \cdot \mathrm{mL}^{-1}$. The airborne concentration of $\beta(1 \rightarrow 3)$-D-glucan was calculated from the airflow through the filter. The mean exposure determined from the two sampling sites was used in the analysis.

\section{Symptoms}

The subjects answered a questionnaire on symptoms present during the preceding 3 months. The symptoms addressed were cough (dry or with phlegm), chest tightness, shortness of breath, irritation in the eyes, nose or throat, and nasal congestion and itchy nose. Questions were also posed on headache, unusual tiredness, wheezy chest and skin problems. For the prevalence of each symptom, a scale of $1-4$ was used: 1 : never or very seldom; 2 : a few times a month; 3 : a few times a week; and 4: daily.

\section{Blood cell counts}

Venous blood was collected in tubes containing ethylene diamine tetra-acetic acid and a differential cell count performed on smears stained with MayGrünwald Giemsa and counted using a light microscope. Lymphocyte subsets were quantified using flow cytometry. Helper/inducer (CD3+CD4+) and cytotoxic/suppressor (CD3+CD8+) T-cell populations were identified. CD3+CD8+ cells were also analysed in combination with a monoclonal antibody binding S6F1, an epitope of the $\alpha$-chain of leukocyte functionassociated antigen-1 complex (CD11a). CD8+ T-cells expressing S6F1 have been classified as cytotoxic cells, whereas CD8+ T-cells showing weak staining for $\mathrm{S} 6 \mathrm{~F} 1$ are either naive cells or suppressor effector cells [17]. Owing to technical problems, numbers of cytotoxic 
T-cells (CD8+S6F1+) could not be determined in two G-low and three G-high subjects.

\section{Markers of granulocyte activation}

Eosinophil cationic protein (ECP) was assayed in serum using a fluorescent enzyme immunoassay technique (CAP ECP FEIA; Pharmacia Diagnostics, Uppsala, Sweden). MPO was assayed using a radioimmunoassay technique (CAP MPO RIA; Pharmacia Diagnostics).

\section{Atopy}

Atopy was determined by measuring the concentration of specific serum immunoglobulin $\mathrm{E}$ antibodies directed against 10 airborne allergens (tree and grass pollen, domestic animal, house dust mite and mould) using a fluorescent enzyme immunoassay technique

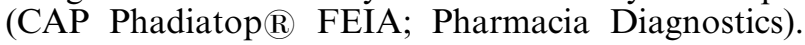
The results were expressed as positive (atopic) or negative (nonatopic) using a specific immunoglobulin $\mathrm{E}$ calibrator with a cut-off value of $0.35 \mathrm{kU} \cdot \mathrm{L}^{-1}$ as reference, in accordance with the manufacturer's instructions.

\section{Cytokine production}

Venous blood was collected in vacutainer tubes containing sodium citrate, a gel barrier and density gradient fluid (CPT ${ }^{\mathrm{TM}}$ tubes; Becton Dickinson, Franklin Lakes, NJ, USA). After centrifugation in a horizontal rotor at $1,500 \times g$ and room temperature for $20 \mathrm{~min}$, the PBMCs were collected and washed twice in Hank's salt solution supplemented with $10 \%$ homologous serum. The PBMCs were then suspended in AIM VR medium (Gibco BRL, Life Technologies, Paisley, UK) supplemented with $4 \times 10^{-5} \mathrm{M} 2$-mercaptoethanol to a final concentration of $2 \times 10^{6}$ cells $\cdot \mathrm{mL}^{-1}$. The cells were incubated with or without phytohaemagglutinin (PHA, Murex Diagnostics Ltd, Dartford, UK) at a final concentration of $250 \mathrm{ng} \cdot \mathrm{mL}^{-1}$ or lipopolysaccharide (E.coli 026:B6; Difco Laboratories, Detroit, MI, USA) at a final concentration of $500 \mathrm{pg} \cdot \mathrm{mL}^{-1}$. PHA was used as the major T-cell stimulus for measurement of interferon gamma (IFN- $\gamma$ ) and IL-4 secretion and lipopolysaccharide as the major monocyte stimulus for the measurement of TNF- $\alpha$ secretion. After incubation for $48 \mathrm{~h}$ in $5 \% \mathrm{CO}_{2}$ at $37^{\circ} \mathrm{C}$, the supernatants were collected and stored at $-25^{\circ} \mathrm{C}$ before cytokine analysis. TNF- $\alpha$ from unstimulated PBMCs was analysed using an enzyme-linked immunosorbent assay (ELISA) kit with a sensitivity of $0.1 \mathrm{pg} \cdot \mathrm{mL}^{-1}$ (Quantikine high sensitive; R\&D Systems, Abingdon, UK). IL-1 $\beta$, IL-4, IL-10, IFN- $\gamma$ and TNF- $\alpha$ from stimulated PBMCs were analysed using PeliKinecompact $^{\mathrm{TM}}$ human cytokine ELISA (Central Laboratory of the Netherlands Red Cross Blood Transfusion Service, Amsterdam, the Netherlands).

Cytokines from PBMCs were analysed for all of the $\mathrm{G}$-low subjects and 14 of the G-high subjects. Cytokine secretion from stimulated and nonstimulated PBMCs was measured on two separate occasions and the means used for analysis. The median intrasubject variation for all of the cytokine analyses was $\sim 30 \%$.

\section{Statistical analyses}

For duplicate measurements on the same person, the coefficient of variation $(\mathrm{CV})$ was calculated in order to evaluate the variability between the first and second measurements. The results are presented as group median with 10th and 90th percentiles in parenthesis. The Mann-Whitney U-test was used to test differences in blood analyses between the G-high and G-low groups. Differences in symptoms were tested using the Chi-squared test. The subgroup of nonatopic subjects was also analysed. The low number of atopic subjects did not warrant separate statistical analysis of this group. The correlation between continuous variables was calculated using the Spearman rank correlation test.

\section{Results}

Table 2 shows the results of the lymphocyte typing. There was a trend toward lower numbers of CD8+ cells as well as of cytotoxic T-cells (CD8+S6F1+) in the G-high group. The proportion of cytotoxic T-cells $(\mathrm{CD} 8+\mathrm{S} 6 \mathrm{~F} 1+)$ was significantly lower in the G-high group compared with the G-low group. Similar results were seen in separate analysis of nonatopic subjects (data not shown). No difference was found for CD4+ T-cells between the G-low and G-high groups.

Secretion of TNF- $\alpha$ from nonstimulated PBMCs was significantly greater in the G-high group compared with the G-low group (10.7 (5.9-15.3) versus 7.3 (4.1-15.9) $\left.\mathrm{pg} \cdot \mathrm{mL}^{-1}, \mathrm{p}<0.05\right)$. A similar tendency was found in the separate analysis of nonatopic subjects, although the difference was not significant (data not shown). The median intrasubject CV between duplicate TNF- $\alpha$ analyses in the G-high group was $31 \%$ (maximum $84 \%$ ) and in the G-low group 21\% (maximum $52 \%$ ). When only subjects with a CV of $<20 \%$ between duplicate samples were compared, a significant difference between the groups was still found $(9.3$

Table 2.-Numbers and proportions of different CD8+ T-lymphocytes in the blood of persons with low (G-low) and high (G-high) levels of $(1 \rightarrow 3)$-D-glucan in their homes

\begin{tabular}{lcc}
\hline & G-low & G-high \\
\hline CD8+ & & \\
$\quad$ Subjects n & 18 & 16 \\
$\quad$ Number $10^{9}$ cells $\cdot \mathrm{L}^{-1}$ & $0.52(0.29-0.72)$ & $0.35(0.19-0.73)$ \\
$\quad$ Proportion \% & $29.5(17.5-41.0)$ & $23.5(12.4-38.9)$ \\
CD8+S6F1+ & 16 & 14 \\
$\quad$ Subjects n & 16 & \\
$\quad$ Number $10^{9}$ cells $\cdot \mathrm{L}^{-1}$ & $0.38(0.15-0.61)$ & $0.14(0.08-0.56)$ \\
Proportion \% & $22.5(12.7-32.1)$ & $12.5(6.0-31.5)^{*}$ \\
\hline
\end{tabular}

Data are presented as median with the 10th and 90th percentiles in parenthesis. G-low: $<2.0 \mathrm{ng} \cdot \mathrm{m}^{-3}$; G-high: $>4.0 \mathrm{ng} \cdot \mathrm{m}^{-3}$. *: $\mathrm{p}<0.05$ versus $\mathrm{G}-$ low. 
(7.4-14.8) $\mathrm{pg} \cdot \mathrm{mL}^{-1}$ in G-high group $(\mathrm{n}=6)$ versus 4.2 (4.1-5.5) $\mathrm{pg} \cdot \mathrm{mL}^{-1}$ in G-low group $\left.(\mathrm{n}=5), \mathrm{p}<0.01\right)$.

Stimulation of the PBMCs with lipopolysaccharide brought about a marked increase in TNF- $\alpha$ secretion but no difference was found between the G-low and G-high groups.

Median secretion of IFN- $\gamma$ was higher and secretion of IL-4 lower from PHA-stimulated PBMCs in the G-high group compared to the G-low group, but no significant differences between the groups were found (IFN- $\gamma$ : $1,305(163-6,520) \mathrm{pg} \cdot \mathrm{mL}^{-1}$ in G-low group versus $1,783(202-10,935) \mathrm{pg} \cdot \mathrm{mL}^{-1}$ in G-high group; IL-4: $7.3(1.1-46.2) \mathrm{pg} \cdot \mathrm{mL}^{-1}$ in $\mathrm{G}-10 \mathrm{w}$ group versus 6.6 $(1.2-26.8) \mathrm{pg} \cdot \mathrm{mL}^{-1}$ in G-high group). The median CV between duplicate samples for IFN- $\gamma$ was $34 \%$ (maximum $129 \%$ ) in the G-low group and $27 \%$ (maximum $133 \%$ ) in the G-high group. For IL-4 the CV was $33 \%$ (maximum 126\%) in the G-low group and $43 \%$ (maximum 112\%) in the G-high group. The consistent relationship between the groups motivated an analysis of the ratio between the two cytokines, as an assessment of the balance of T-helper cell (Th) type 1- and 2 -associated activation. There was a nonsignificant tendency for a higher IFN- $\gamma / \mathrm{IL}-4$ ratio in the G-high group compared to the G-low group (228 (86-675) versus 129 (54-554)). When nonatopic subjects were analysed separately, the IFN- $\gamma / \mathrm{IL}-4$ ratio was significantly higher in the G-high group compared to the G-low group (247 (116-734) versus $126(34-514), \mathrm{p}<0.05)$. A significant relationship was also found between the IFN- $\gamma /$ IL- 4 ratio and the amount of $\beta(1 \rightarrow 3)$-D-glucan measured in the home $(\mathrm{r}=0.47, \mathrm{p}<0.05)$. Figure 1 illustrates this relationship, excluding one subject with a very high amount of $\beta(1 \rightarrow 3)$-D-glucan at home $\left(51.7 \mathrm{ng} \cdot \mathrm{m}^{-3}\right.$, IFN- $\left.\gamma / \mathrm{IL}-4=172 ; \mathrm{r}=0.50, \mathrm{p}<0.05\right)$.

No significant differences were found between the G-high and G-low groups regarding secretion of IL-10 or IL-1 $\beta$ from PBMCs, ECP or MPO levels in serum, differential cell counts in blood, or the prevalence of symptoms.

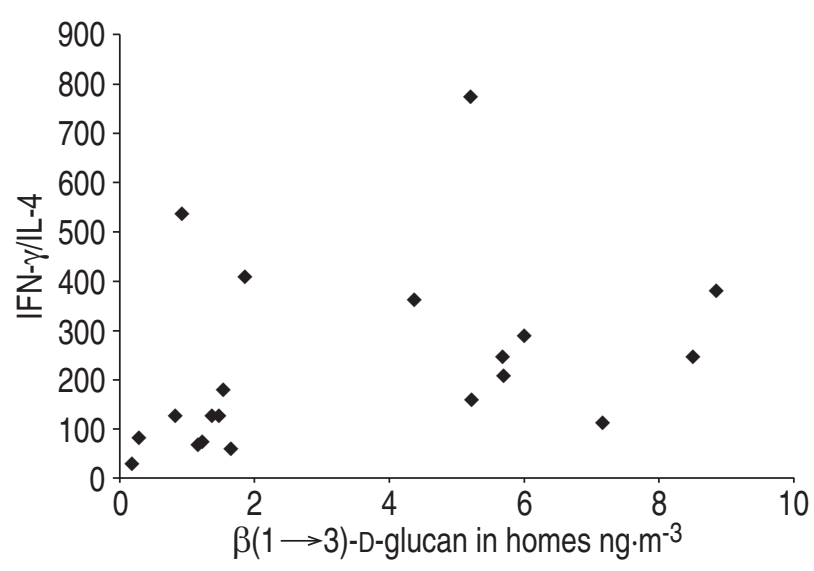

Fig. 1.-Relationship between home $\beta(1 \rightarrow 3)$-D-glucan levels and the ratio between interferon gamma (IFN- $\gamma$ ) and interleukin (IL)-4 secretion from phytohaemagglutinin-stimulated peripheral blood mononuclear cells in nonatopic subjects, excluding one subject with a very high amount of $\beta(1 \rightarrow 3)$-D-glucan at home $\left(51.7 \mathrm{ng} \cdot \mathrm{m}^{-3}\right.$, IFN- $\gamma / \mathrm{IL}-4=172$ ).

\section{Discussion}

The recruited persons represent a biased population sample as they were aware of problems related to mould exposure at home or answered an advertisement requesting the participation of persons with a mould problem at home. The population recruited from the previous study [10] reported a slightly higher prevalence of some symptoms such as those involving the nose and central nervous system-related symptoms as compared to the overall population in the previous study. For other symptoms such as throat irritation and cough, the prevalences were similar. Regarding the population recruited by advertising, it is reasonable to presume a higher prevalence of symptoms in this group compared to a random population sample. The assignment into exposure groups, however, was made according to measurements of $\beta(1 \rightarrow 3)$-D-glucan in the subjects' homes and not according to subjective reporting of mould problems at home. There was a similar distribution of subjects into the G-high and G-low groups from the two recruitment groups (see Methods section) and there were no differences in symptom prevalence between the G-high and G-low groups. Taken together, it is thus unlikely that a selection bias according to symptoms or route of recruitment accounted for the differences found in inflammatory marker levels in the blood between the G-low and G-high groups.

The results suggest an effect on lymphocytes as the G-high group showed a lower proportion of cytotoxic CD8+ T-cells in their blood. A previous study showed that only CD8+ T-cells expressing S6F1 could migrate through an endothelial layer [18], and another study demonstrated that CD8+S6F1+ T-cells exhibited a cytotoxic effect [17]. The reduced proportion of these cells in blood from the G-high group could thus be the result of increased trapping in the lung due to inflammatory activity in the airways. Indeed, FIREMAN et al. [19] found an inverse relationship in the number of CD8+S6F1+ T-cells when they compared blood and bronchoalveolar lavage fluid from patients with idiopathic pulmonary fibrosis. The relationship between mould exposure at home and effects on blood lymphocytes has been explored in a previous study [11]. This study examined children, and, contrary to the present results, the data showed a slightly reduced number of CD4+ T-cells and slightly increased number of CD8+ $\mathrm{T}$-cells, resulting in a lower CD4+/CD8+ ratio among mould-exposed children. The reason for this discrepancy is not clear; differences in exposure or in the reaction of adults and children are possible explanations.

Some studies have shown a relationship between living in a house with mould and/or dampness and increased risk of atopy in children [12-14]. This relationship is supported by data from an experimental study in mice, where exposure to $\beta(1 \rightarrow 3)$-D-glucan induced increased expression of messenger ribonucleic acid encoding IL-10, a Th2-driving cytokine, in lung tissue cells, whereas expression of IL-12, promoting IFN- $\gamma$ production, was depressed [20]. In the present study, however, the nonatopic G-high group exhibited a higher IFN- $\gamma / \mathrm{IL}-4$ ratio than the nonatopic G-low group and this ratio correlated with the level of 
$\beta(1 \rightarrow 3)$-D-glucan in the home. This suggests that, in nonatopic subjects, $\beta(1 \rightarrow 3)$-D-glucan exposure at home is not associated with a Th2 pattern of cytokine secretion. The reason why a different ratio between the G-high and G-low groups was found only among nonatopic subjects could be that, among atopic subjects, secretion of IFN- $\gamma$ as well as IL-4 has a tendency to be increased in the G-high group compared to the G-low group.

In the present study, effects on secretion of $\mathrm{TNF}-\alpha$ from nonstimulated PBMCs and changes in blood T-cell subsets and the IFN- $\gamma / \mathrm{IL}-4$ ratio in relation to $\beta(1 \rightarrow 3)$-D-glucan levels in the subjects' homes were found. In accordance with a previous study in an area of terraced housing [10], the G-high group exhibited a higher concentration of MPO in their serum than the G-low group, but the difference was not significant. For the other inflammatory markers studied, no significant effects were found. This suggests that there is no massive inflammatory response among subjects exposed to $\beta(1 \rightarrow 3)$-D-glucan in their homes, at the levels present in this study, a conclusion supported by the lack of an association between the extent of reported symptoms and $\beta(1 \rightarrow 3)$-D-glucan levels in the home.

The relationships between airborne $\beta(1 \rightarrow 3)$-D-glucan and inflammatory cytokines do not necessarily imply that mould is the causative agent. The conditions required for mould growth also promote the growth of other microorganisms and the formation of volatile organic compounds from building material [21]. In previous studies, a relationship between the amount of endotoxin from Gram-negative bacteria in floor dust and the severity of asthma was found [22-24]. Endotoxin was not analysed in the present study since it is the authors' experience from earlier studies that airborne endotoxin levels in dwellings, as sampled using the present technique, are generally below the detection limit of the assay used $\left(0.6 \mathrm{pg} \cdot \mathrm{m}^{-3}\right)$.

Conversely, mould cells contain a number of biologically active agents. Mycotoxins from Mycobacterium murale and Stachybotrys atra have been related to symptoms and disease $[25,26]$. The cell wall substance $\beta(1 \rightarrow 3)$-D-glucan itself has important effects on the immune system [27]. Further work is needed to assess the role of these potentially inflammagenic agents from microorganisms in symptoms related to indoor exposures.

In summary, the present results suggest a relationship between living in homes with higher levels of $\beta(1 \rightarrow 3)$-D-glucan and changes in some parts of the inflammatory and immunological systems. In nonatopic persons, a dose/response relationship was found between the interferon gamma/interleukin-4 ratio and the amount of $\beta(1 \rightarrow 3)$-D-glucan measured in the home. The increased tumour necrosis factor- $\alpha$ secretion from blood cells and reduced proportion of cytotoxic CD8+ $\mathrm{T}$-cells in the blood suggest upregulated inflammatory activity in the airways related to mould exposure.

Acknowledgements. The authors thank D Söderberg, G. Arvidsson, E. Kerekes and R.M. Olofsson for skilful technical management.

\section{References}

1. Platt SD, Martin CJ, Hunt SM, Lewis CW. Damp housing, mould growth, and symptomatic health state. BMJ 1989; 298: 1673-1678.

2. Dijkstra L, Houthuijs D, Brunekreef B, Akkerman I, Boleij JSM. Respiratory health effects of the indoor environment in a population of Dutch children. Am Rev Respir Dis 1990; 142: 1172-1178.

3. Brunekreef B. Associations between questionnaire reports of home dampness and childhood respiratory symptoms. Sci Total Environ 1992; 127: 79-89.

4. Jaakkola JJK, Jaakkola N, Ruotsalainen RH. Home dampness and moulds as determinants of respiratory symptoms and asthma in pre-school children. $J$ Expo Anal Environ Epidemiol 1993; 3: 129-142.

5. Hu FB, Persky V, Flay BR, Richardson J. An epidemiological study of asthma prevalence and related factors among young adults. J Asthma 1997; 34: 67-76.

6. Williamson IJ, Martin CJ, McGill G, Monie RD, Fennerty AG. Damp housing and asthma: a casecontrol study. Thorax 1997; 52: 229-234.

7. Rylander R. Sick building syndrome. In: Basomba A, Sastre J, eds. XVI European Congress of Allergology and Clinical Immunology. Monduzzi Editore, Bologna, 1995; pp. 409-414.

8. Douwes JA, Zuidhof A, Doekes G, et al. (1 $\rightarrow 3)-\beta$-Dglucan and endotoxin in house dust and peak flow variability in children. Am J Respir Crit Care Med 2000; 162: 1348-1354.

9. Hirvonen MR, Ruotsalainen M, Roponen M, et al. Nitric oxide and proinflammatory cytokines in nasal lavage fluid associated with symptoms and exposure to moldy building microbes. Am J Respir Crit Care Med 1999; 160: 1943-1946.

10. Thorn J, Rylander R. Airways inflammation and glucan in a rowhouse area. Am J Respir Crit Care Med 1998; 157: 1798-1803.

11. Dales R, Miller D, White J, Dulberg C, Lazarovits A. Influence of residential fungal contamination on peripheral blood lymphocyte populations in children. Arch Environ Health 1998; 53: 190-195.

12. Schafer T, Kramer U, Dockery D, Vieluf D, Behrendt $\mathrm{H}$, Ring J. What makes a child allergic? Analysis of risk factors for allergic sensitization in preschool children from East and West Germany. Allergy Asthma Proc 1999; 20: 23-27.

13. Garrett MH, Rayment PR, Hooper MA, Abramason MJ, Hooper BM. Indoor airborne fungal spores, house dampness and associations with environmental factors and respiratory health in children. Clin Exp Allergy 1998; 28: 459-467.

14. Savilahti R, Uitti J, Roto P, Laippala P, Husman T. Increased prevalence of atopy among children exposed to mold in a school building. Allergy 2001; 56: 175179.

15. Rylander R, Persson K, Goto H, Yuasa K, Tanaka S. Airborne $\beta, 1-3$ glucan may be related to symptoms in sick buildings. Indoor Environ 1992; 1: 263-267.

16. Tamura H, Arimoto $\mathrm{Y}$, Tanaka S, Yoshida $\mathrm{T}$, Obayashi T, Kawai T. Automated kinetic assay for endotoxin and $(1 \rightarrow 3)$ - $\beta$-D-glucan in human blood. Clin Chim Acta 1994; 226: 109-112.

17. Morimoto C, Rudd CE, Letvin NL, Schlossman SF. A novel epitope of LFA-1 antigen which can 
distinguish killer effector and suppressor cells in human CD8 cells. Nature 1987; 330: 479-482.

18. Berman JS, Mahoney K, Saukkonen JJ, Masuyama J. Migration of distinct subsets of CD8+ blood T cells through endothelial cell monolayers in vitro. J Leukoc Biol 1995; 58: 317-324.

19. Fireman E, Vardinon N, Burke M, et al. Predictive value of response to treatment of T-lymphocyte subpopulations in idiopathic pulmonary fibrosis. Eur Respir J 1998; 11: 706-711.

20. Wan G-H, Li C-S, Guo S-P, Rylander R, Lin R-H. An airborne mould-derived product, $\beta$-1,3-D-glucan, potentiates airway allergic responses. Eur J Immunol 1999; 29: 2491-2497.

21. Korpi A, Pasanen AL, Pasanen P. Volatile compounds originating from mixed microbial cultures on building materials under various humidity conditions. Appl Environ Microbiol 1998; 64: 2914-2919.

22. Michel O, Ginanni R, Duchateau J, Vertongen F, Le Bon B, Sergysels R. Domestic endotoxin exposure and clinical severity of asthma. Clin Exp Allergy 1991; 21: 441-448.

23. Michel O, Kips J, Duchateau J, et al. Severity of asthma is related to endotoxin in house dust. $\mathrm{Am}$ J Respir Crit Care Med 1996; 154: 1641-1646.

24. Rizzo MC, Naspitz CK, Fernández-Caldas E, Lockey RF, Mimiça I, Solé D. Endotoxin exposure and symptoms in asthmatic children. Pediatr Allergy Immunol 1997; 8: 121-126.

25. Andersson MA, Nikulin M, Koljalg U, et al. Bacteria, moulds, and toxins in water-damaged building materials. Appl Environ Microbiol 1997; 63: 387-383.

26. Etzel RA, Montaña E, Sorenson WG, Kullman GJ, Allan TM, Dearborn DG. Acute pulmonary hemorrhage in infants associated with exposure to Stachybotrys atra and other fungi. Arch Pediatr Adolesc Med 1998; 152: 757-762.

27. Rylander R, Lin R-H. ( $1 \rightarrow 3)-\beta-D-G l u c a n$ - relationship to indoor air-related symptoms, allergy and asthma. Toxicology 2000; 152: 47-52. 